\title{
THE EFFECT OF OPENING SHAPES ON THE STABILITY OF UNDERGROUND TUNNELS: A FINITE ELEMENT ANALYSIS
}

\author{
*Abdullah H Alsabhan ${ }^{1}$, Md Rehan Sadique², Shahbaz Ahmad ${ }^{3}$, Shamshad Alam ${ }^{1}$ and Abobaker S Binyahya ${ }^{1}$ \\ ${ }^{1}$ Department of Civil Engineering, College of Engineering, King Saud University, Riyadh, Saudi Arabia; \\ ${ }^{2}$ Civil Engineering Department, Faculty of Engineering, Aligarh Muslim University-202002(UP), India; \\ ${ }^{3}$ Department of Civil Engineering, Texas A\&M University, College Station, TX-77840, USA
}

*Corresponding Author, Received: 17 July 2021, Revised: 02 Oct. 2021, Accepted: 17 Oct. 2021

\begin{abstract}
Tunnel construction and development has long been an important component of smart cities and modern sustainable development projects around the world. Despite major advances in tunneling technologies, tunneling in rocks remains one of the most mammoth tasks for a geotechnical engineer to complete. Nowadays, all new complex and significant structures are designed and analyzed through finite element techniques. In the present study, numerical simulations have been carried out using the finite element code ABAQUS. Around the tunnel, a specified region of rock mass has been discretized into about 34000 elements. The Continuum Three Dimensional Eight Nodded Reduced integrated (C3D8R) elements were used to model the Tunnel. The effect of the shape of tunnel opening has been studied in three dimensional models using the Elastic Approach Solution Technique. A circular, oval, horse-shoe and square opening of a tunnel have been analyzed. In the current investigation, the behavior of flat head tunnels was also taken into account for comparison purposes. The crown of a flat head and round tubes of equivalent dimensions have shown the most deformation. On the other side, the oval shape has been found to have the fewest deformations at the crown of the opening. Furthermore, the horse-shoe opening, which is the most commonly used tunnel opening shape, has somewhat higher distortion than the oval opening.
\end{abstract}

Keywords: Tunnel, Opening Shape, Finite Element, ABAQUS

\section{INTRODUCTION}

From stone age to the modern sustainable developments, mankind has excavated caverns and tunnels in the earth for an innumerable purpose. Historically, from ancient safety and storage tunnel up to the modern underground cities, tunneling has travelled a very long change in term of methods and purpose of excavation. Moreover, evidence had shown that Stone Age people, Egyptian, Romans and other civilizations had developed different tunneling technologies to obtained metals and gold [1,2]. With modern excavation tools and analysis techniques both soil and rock tunneling has become an inevitable part of smart cities [3,4]. Researchers have studied the response of tunnels due to internal and external loadings [5,6]. Effects of soil properties and pore water pressure had also been evaluated [7].

Under in-situ conditions, rock masses are in triaxial compression due to tectonic stresses [8]. Significantly high in-situ stress values result in a very risky situation of rock bursting in excavations and tunneling [9]. The confinement on one side will be removed by tunneling, resulting in a high stress gradient on the rocks. The removal of rock mass for tunneling will result in strong strains on one side of the rocks that make up the tunnel wall and ceiling, but there will be no counteracting force. These stress gradients may trigger rock bursts in deep mines and deeper tunnels, where rock fragments can suddenly and violently explode in seismic events that are commonly measured at 2 to 4 on the Richter scale [10].

In terms of rock mass attributes, through-situ condition, hydraulic gradient, and geological terrain, tunneling in rocks is complicated. As a result, a short paper cannot address all of the mechanics of tunnel design and construction. Hundreds of pages have been given to the problem, analysis, and design of tunneling under various prevailing conditions in dozens of works. There are, nevertheless, a few fundamental notions that apply to the design process. In addition, threedimensional finite element modeling has grown as a potent tool for simulating similar field conditions to a far greater extent. Response of rock cut slopes, tunneling and other man-made disturbance can be fairly simulated and understanding of mitigation and support system can be well established.

In the present paper, a three-dimensional finite element model of rock mass has been developed in finite element code ABAQUS [11]. The diameter of tunnel has been taken equivalent to diameter of Pir Panjal Tunnel in Jammu \& Kashmir (India). Pir Panjal Tunnel is a Railway Tunnel in rock, which is still in its construction phase [12]. Elastic approach of analysis of underground opening has 
been followed up in the present study. Which means the material is homogenous, isotropic and perfectly elastic. Moreover, it follows the linearity between stress and strain [13]. It has a simple assumption that rock mass can be represented by an equivalent continuum and it will respond as brittle material as defined by the brittle-ductile transition.

\section{FINITE ELEMENT MODELLING}

The evaluation of stress distribution, around the underground openings, is important for designing a proper support system. In such a situation, finite element analysis is found to be quite efficient in handling such complexities [14].

Geotechnical property and tunneling technique modeling is a complex numerical problem [15-20]. Elsayed [21] used a 2-D finite element analysis of tunneling to represent two phases of the tunneling process, namely the excavation phase and the interaction phase. The final rock mass pressure acting on the lining, as well as the deformations and stresses of the rock-liner system, were determined. Cavalaro et al. [22] used FEM to simulate the effect of contact deficiencies between segmented tunnel liner during tunnel building and the resulting damage procedure with Tunnel Boring Machine. Kivi et al. [23] used 3-D finite element analysis to study the impact of the central beam column (CBC) on the stiffness of the supporting tunnel system in the Tehran metro. Liu et al. [24] used numerical methods to determine the impact of ground movement and construction in a shield tunneling and expanding construction. Finite element analysis was utilized by Wang et al. [25] and Wang et al. [26] to forecast surface settlement above a tunnel in clay soil and the effect of tunneling driven ground movement on buried pipes. Surface settlement and vertical displacement are also estimated using the 2-D FEA at various places and levels throughout the tunnel system. Elasto-plastic materials are used in the constitutive model for this analysis. A Mohr-Coulomb type yielding function is used, as well as a DruckerPrager type plastic potential function. The tunnel liner is represented using a linear constitutive model.

\section{SHAPES OF TUNNEL OPENING}

Tunneling may be regarded as one of the most hazardous, risky and expensive projects in construction engineering. Hence, pre-excavation extensive planning and surveying is the vital part of the tunneling project. Nevertheless, a long duration is required, often years between the initial idea and the beginning of the excavation of a tunnel project. In order to assess the stability of such openings, it is necessary that the stresses and deformations in the rock mass be accurately analyzed by adopting the realistic rock mass parameters in the analysis, rather than using their approximate or average values [27]. The crosssection of any underground opening may be decided with consideration of the following factors;

(i) The purpose for which the tunnel will serve.

(ii) Depth or location of the opening beneath the ground level

(iii) The state of stress at in-situ ground condition

(iv) Available technology and economics available for the project

Hence, the shape of the tunnel is an important and governing factor in any tunneling project, different possible shapes of tunnel openings are discussed here and shown in Figure 1. (a)
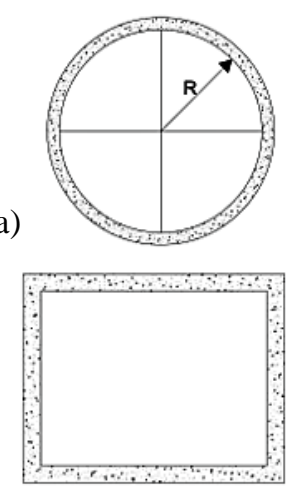

(c) (b)
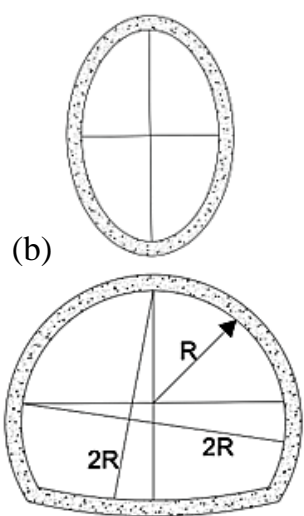

(d)
Fig. 1. Different Shapes of Tunnel (a) Circular, (b) Oval, (c) Rectangular, (d) Horse Shoe

(a) Circular Section: Circular tunnels are frequently used for carrying water, sewage gases and fluidized ores etc. Circular tunnels are not preferred as traffic tunnels. A circular section will offer greater resistance to external pressure. Hence, in highly unstable squeezing ground conditions, such as soft clay or sand, circular section is preferably adopted [28]. Tunnel sections with small curvature radius will have high stress concentration. In underground rock excavations using Tunneling Boring Machines (TBM), only circular cross sections are feasible due to practical restrictions.

(b) Elliptical Section: This type of opening is preferred in soil rather than rock. These tunnels serve as water sewage conditions. They are difficult to construct. They cannot be used as traffic tunnels because of their narrow base. 
Nowadays, multi-purpose tunnels are designed with elliptical openings, which serve different purposes in different layers.

(c) Oval Section: These openings may be considered as modified elliptical section with narrow cross sections at the bottom of the tunnel. Due to its best suitability for sewage carrying, it is opted to counter urban and flash floods. To maintain a self-cleansing velocity of flow of sewage both in dry and rainy seasons is easier in this section. These types of opening are able to resist external as well as internal pressure due to their circular walls. However, tunnels with an oval cross-section are difficult to construct.

(d) Horse Shoe Section: This design features a semi-circular roof, arched sides, and a curving invert. They're most commonly used as traffic tunnels for highways and railways. Constructing these tunnels is equally tough. The maximum number of modern transport tunnels are either horse shoe (HS) or modified horse shoe section

(e) Flat Top Section: Tunnels with a flat roof or a square or rectangular aperture are uncommonly excavated. The reason for this is that as the span lengthens, the rock in the center exerts less force, making a flat-roofed tunnel more vulnerable to collapse from the tunnel's crown. In heavily stratified rock, such as shale, the roof is frequently cut flat to take advantage of the rock's natural tendency to break along bedding planes. The tunnel would be less likely to collapse if it was cut along bedding planes and subsequently supported, as opposed to an alternative geometry that cut through the rock bedding, making it more unstable.

\section{ANALYSIS AND DISCUSSION}

The geometric model of the tunnel produced in ABAQUS/CAE, as shown in Figure 2, was used to perform three-dimensional finite element analysis. The model has dimension of 30m in each direction with tunnel opening of $8 \mathrm{~m}$ diameter.

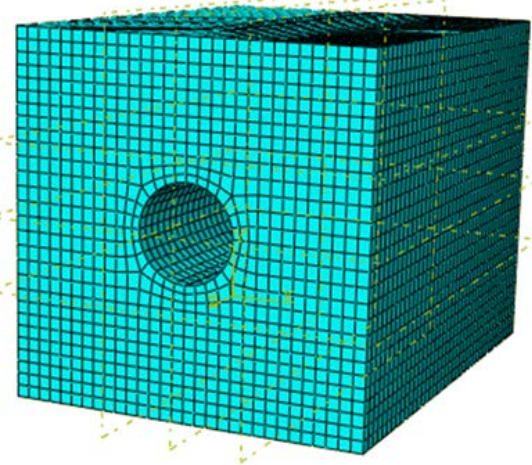

Fig. 2. Element characterization
In order to better understand the effect of opening shape on tunnel behavior, four alternative opening shapes were explored in this study. To avoid the effect of tunnel opening size, all tunnels were assumed to have a maximum horizontal opening of roughly 8 meters. Furthermore, the effect of joint orientation and spacing is assumed to be ignored under isotropic and homogenous ground conditions. Figure 3 shows the results of a mesh convergence study to determine the best appropriate element size for finite element analysis. Maximum stress observed in the simulation has been plotted against the number of element considered along the thickness. It has been started with considering six elements along the length of tunnel, which means an element size of $5 \mathrm{~m}$. The number of element along the length of tunnel has been increased further to $10,15,20,25,30,40$ and 50. However, after 30 elements no significant increased has been reported in the stress value. For 30 elements along the thickness, the simulation has total 32800 elements. For 40 and 50 it increases to 66200 and 161068 elements. Hence, an element of $1 \mathrm{x} 1 \mathrm{x} 1 \mathrm{~m}^{3}$ has been found to be most suitable considering the optimization of the total number of elements in the present analysis. It has to be restated here, the present investigation has been absolutely focused on the shape effect of tunnel opening, hence the relative magnitude or ratio of stress and displacement is very significant rather than individual values.

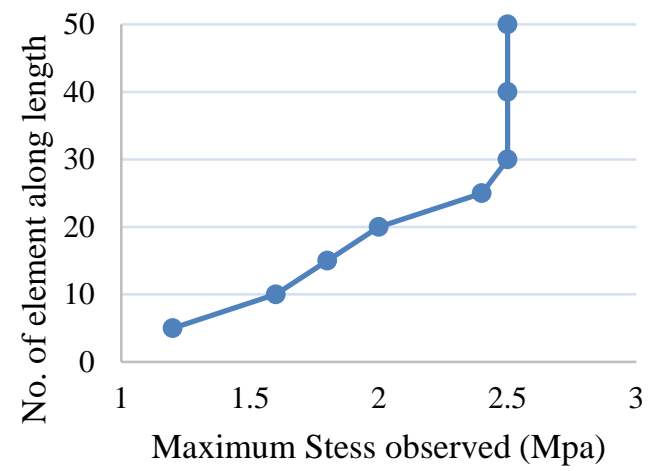

Fig. 3. Mesh Convergence Analysis

Table 1: Material characteristics of rock.

\begin{tabular}{ccc}
\hline Characteristics & Granite & Sandstone \\
\hline Density (kg/m3) & 2630 & 2300 \\
Young's Modulus & 36 & 28 \\
(GPa) & & \\
Poisson's Ratio & 0.3 & 0.2 \\
Compressive & 160 & 78.5 \\
strength (MPa) & & \\
\hline
\end{tabular}


The analysis has been performed for two different rock types, i.e. Granite and Sandstone. The mechanical characteristics of rocks have been adopted from Zhao [29] and Zhang et al [30] respectively. It has been summarized in the Table 1. In order to validate the procedure of the current numerical analysis, it has been validated with the experimental study conducted by Xiang et al [31]. Xiang et al had carried out a comparative analysis for the loading and unloading on a tunnel model, further they had also performed simulation study. A similar model has been developed in Abaqus
[11] with same boundary and loading conditions, as shown in Fig. 4(a). Finite element characterization has been done with identical material properties, shown in Fig. 4(b). A comparative graph of load - deformation relationship between the experimental study of Xiang et al [31] and the present numerical analysis has been plotted in Fig. 5. A close correlation has been reported in the studies. Henceforth, the present numerical procedure has been validated.

(a)

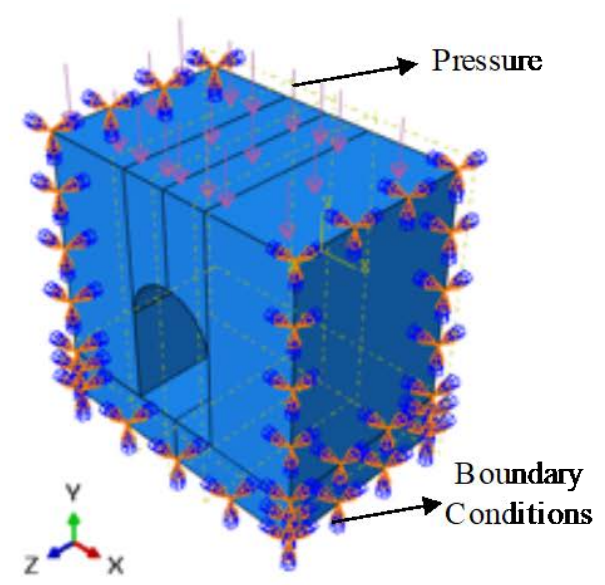

(b)

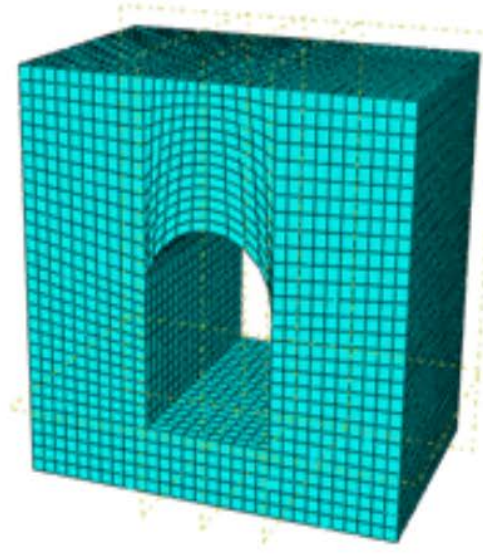

Fig. 4. Finite element model (a) load and boundary conditions (b) element characterization

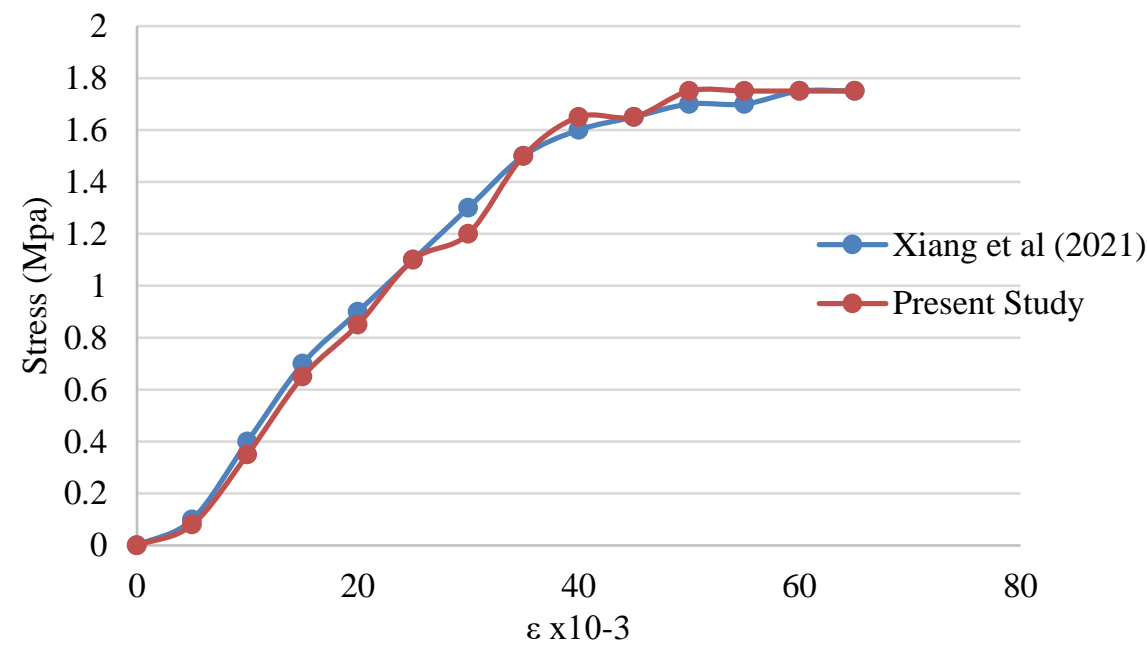

Fig. 5. Comparative stress-strain graph for validation 


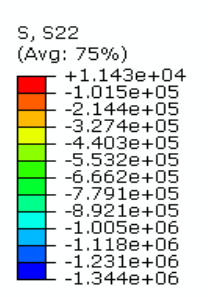

(a) Oval Opening

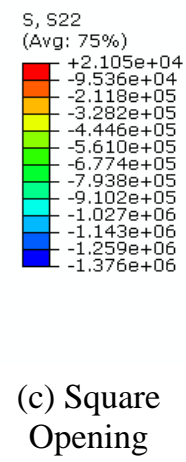

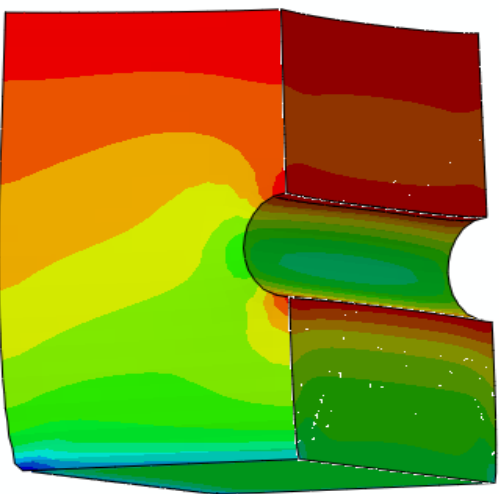

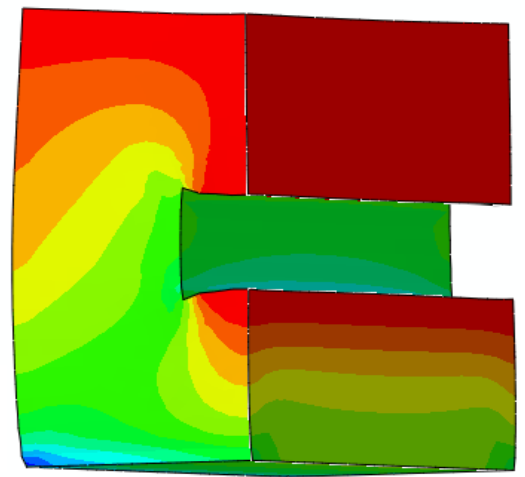

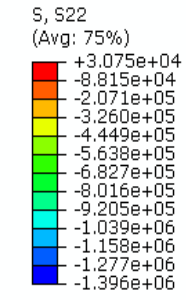

(b) Circular Opening

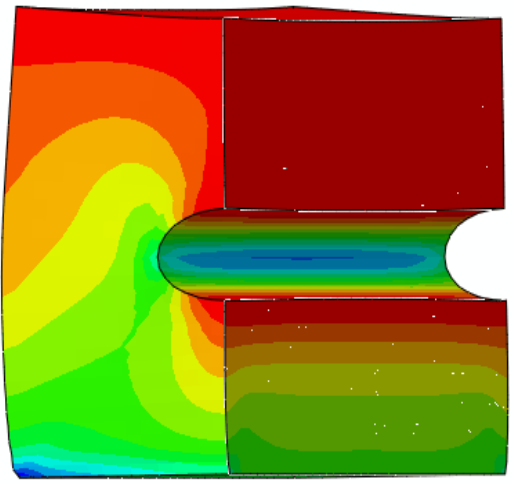

(d) Horse Shoe Opening

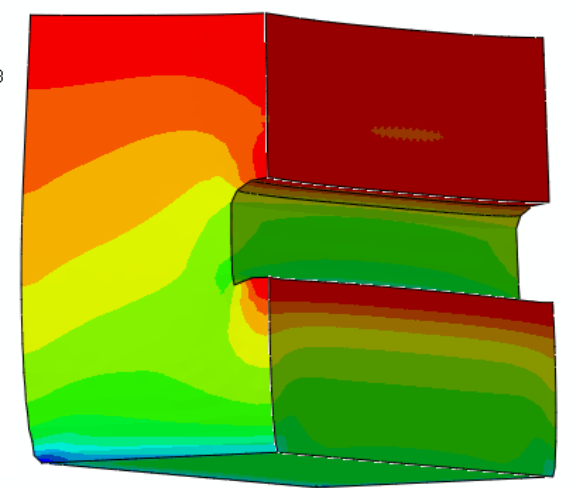

Fig. 6. Principal stress for granite at various tunnel openings

Contour plots of variation in major principle stress for Granite rock have been shown in Figure 6. The crown and the invert portion of the openings are under tensile stresses. However, significant compressive stress has been reported in walls, only in the case of circular opening. For elastic static analysis, if considering overburden pressure as the main cause of deformation and failure, the crown may be considered as the most critical part of the tunnel. Horse-shoe (HS) shaped opening has been found in least stress condition. Tensile stresses in the case of oval opening were 5.18 times that of HS. However, circular and square openings have peak stresses 13.95 and 9.54 times greater than that of oval.

Similar, results were also plotted when tunneling had been considered in sandstone, Figure 7. Herein also, the HS has been reported to have the least peak stress and the oval opening is 2.17 times higher. Furthermore, circular opening has 11.40 times while square opening has 8.40 times higher peak stresses. Hence, if a concrete lining has to be provided inside the tunnel, it should be thicker for circular opening, and thinner for the HS. The deformation contour of the tunnels for opening in granite has been plotted in Figure 8 while for sandstone it has been shown up in Figure 9. In both rock types, the oval shaped opening has the least deformation followed by HS, circular and rectangular at the crown of the tunnel. The deformation in oval and HS may be minimized due to the arch action of opening. However, at the point of invert circular and square openings seemed to be more stable than that of HS and oval. The inward bulging is minimum in the case of square opening of the tunnel. 


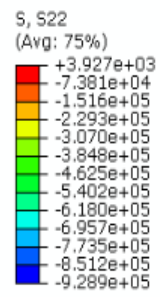

(a) Oval Opening
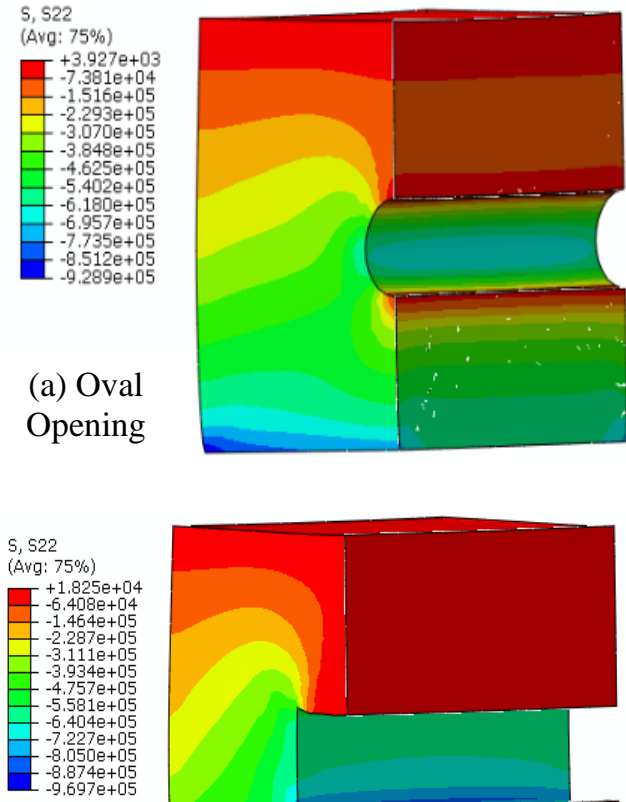

(c) Square Opening

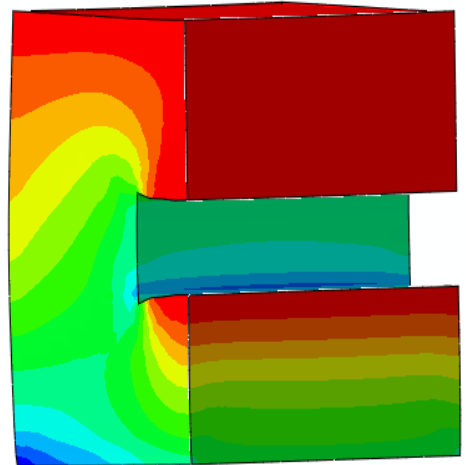

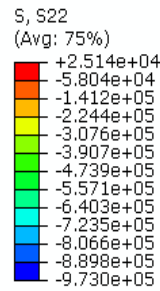

(b) Circular Opening

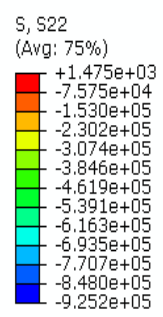

(d) Horse Shoe Opening
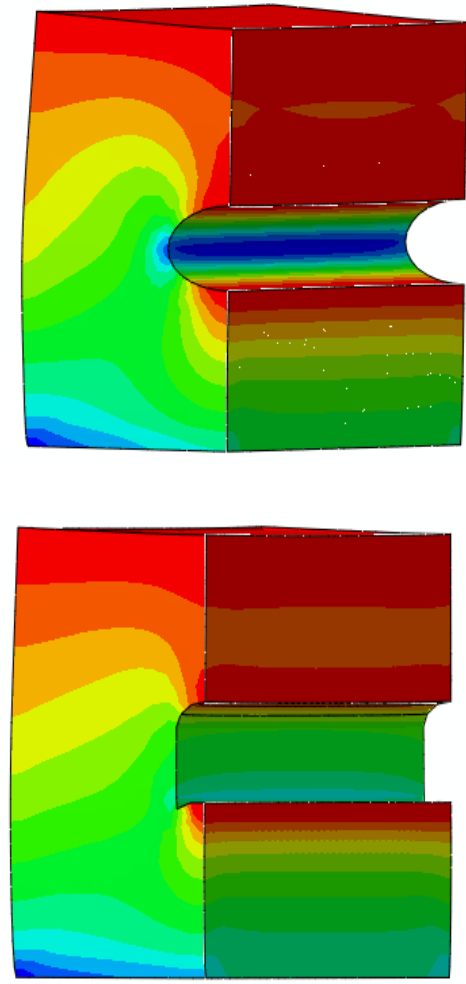

Fig. 7. S22 Sandstone Contour for different tunnel openings

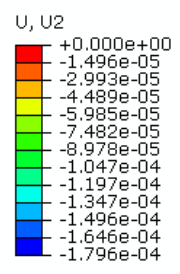

(a) Oval Opening
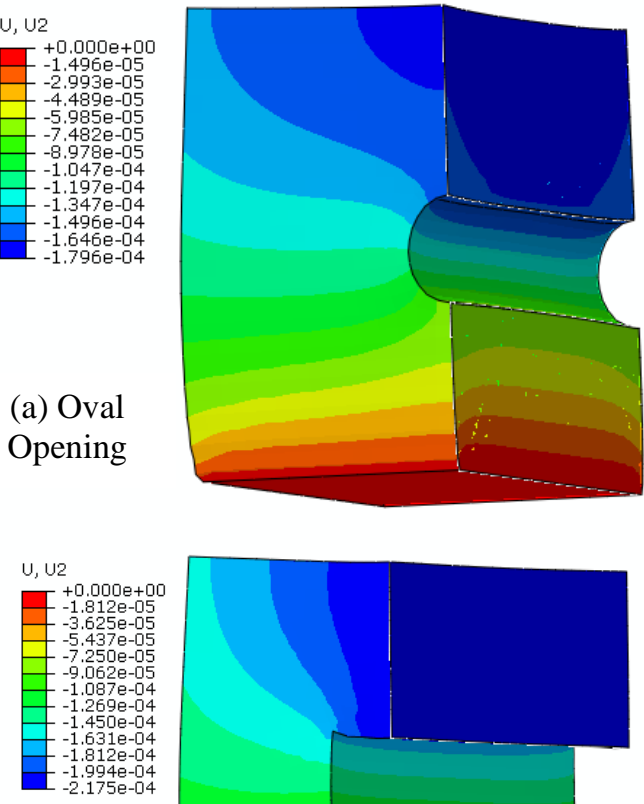

(c) Square Opening

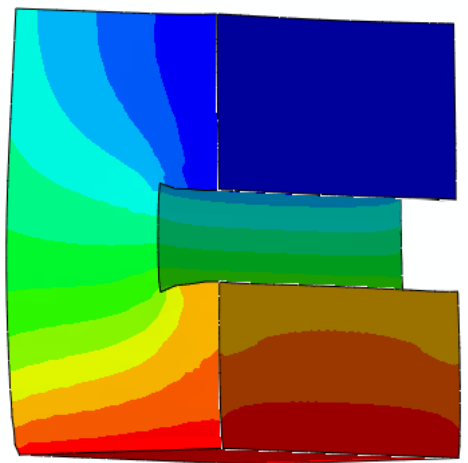

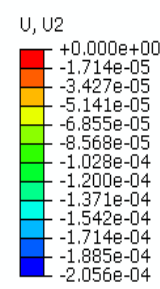

(b) Circular Opening

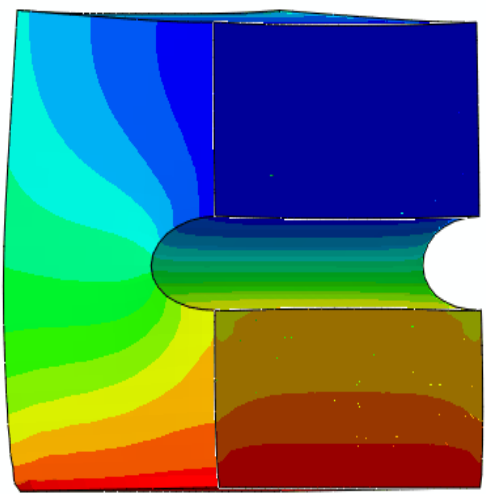

(d) Horse Shoe Opening

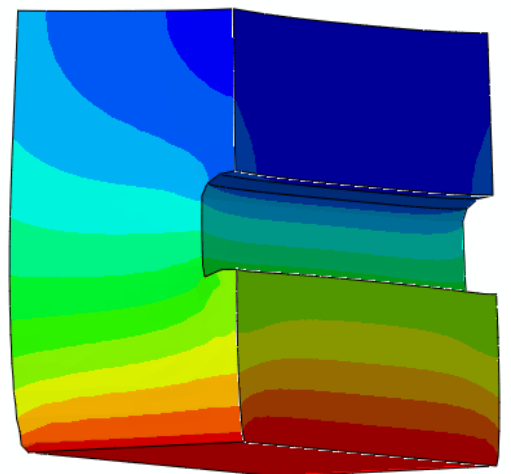

Fig. 8. Deformation Contour in Granite for different tunnel openings 


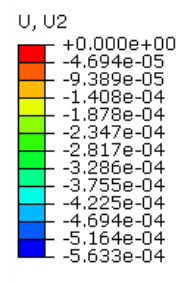
(a) Oval Opening
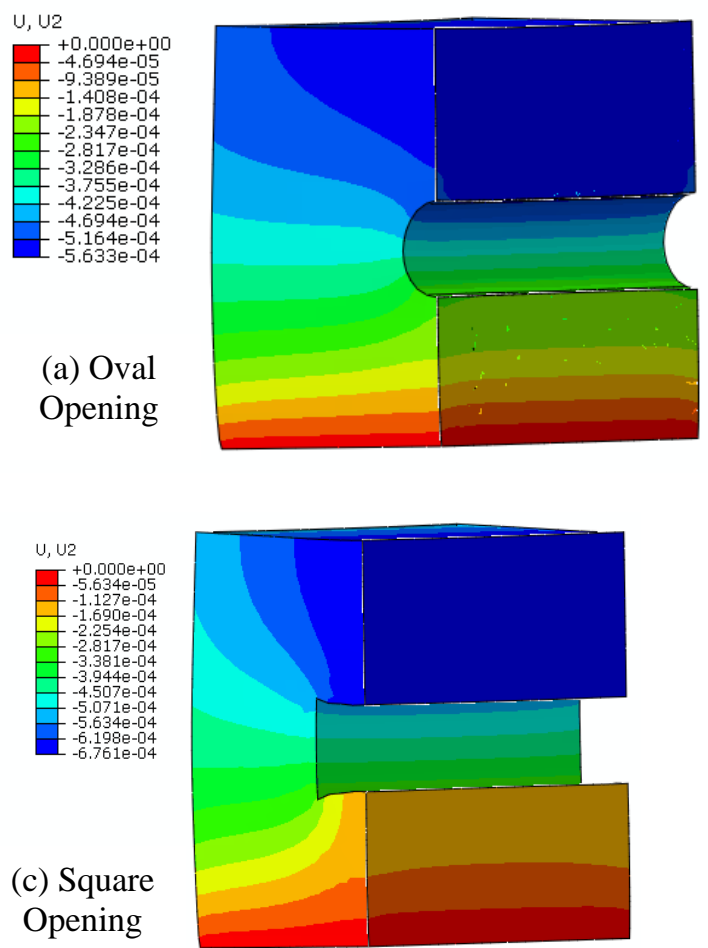

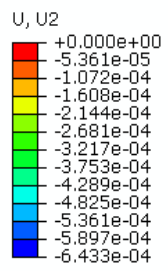

(b) Circular
Opening

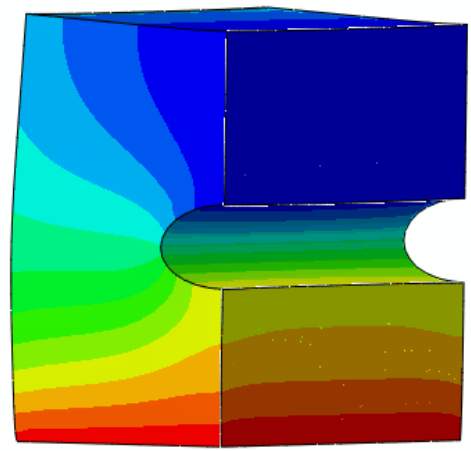

(d) Horse Shoe Opening

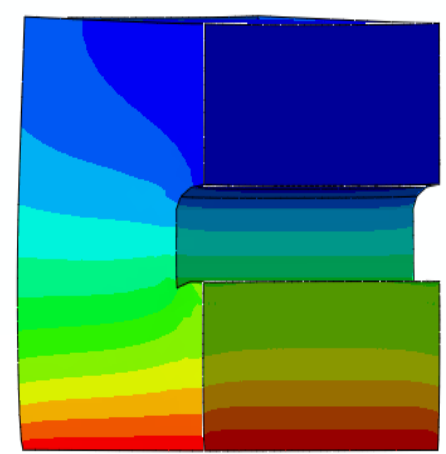

Fig. 9. Deformation Contour in Sandstone for different tunnel openings

Stress distribution along the cross-section has been evaluated by considering all nodes from the mid-point of the left wall to the mid-point of the right wall crossing through the crown, which are lying on the face. The Rate of Fall in stress was sharp in oval and HS, while the rate of fall was relative slow for other two openings, Figure 10.

However, in square sections, stresses on side walls have been reported nearly constant. Deformations for the same nodes are presented in

Distance from Crown (m)

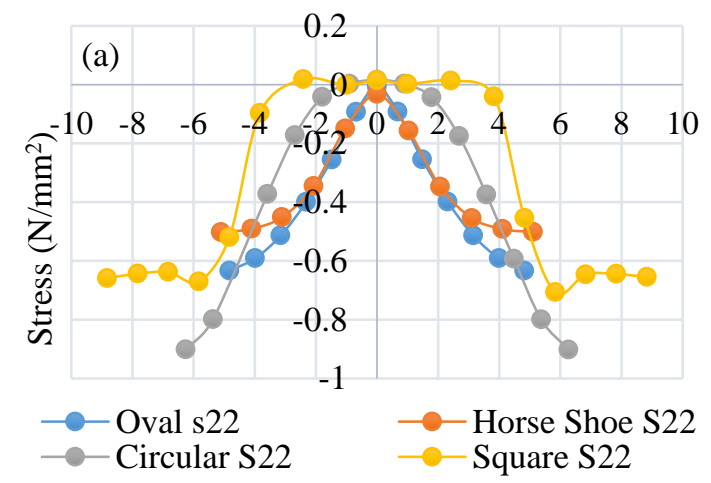

Fig. 11 (a) and 11 (b). It's worth noting that the difference in deformation magnitude is entirely due to the rock type. Because granite has a higher density and a lower toxicity ratio than sandstone, openings in granite have less deformation. The largest deformation is in the square shape, which is closely followed by the circular opening. Meanwhile, deformations in the oval and HS openings have been observed.

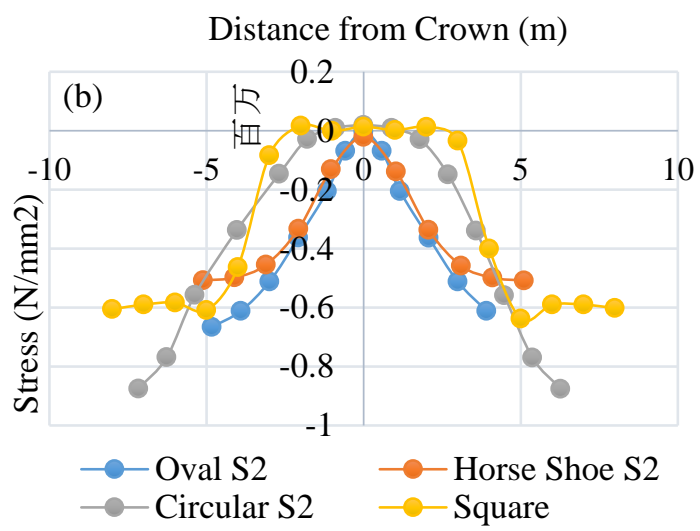

Fig. 10. Stress Distribution across the crown of opening in (a) Granite (b) Sandstone 

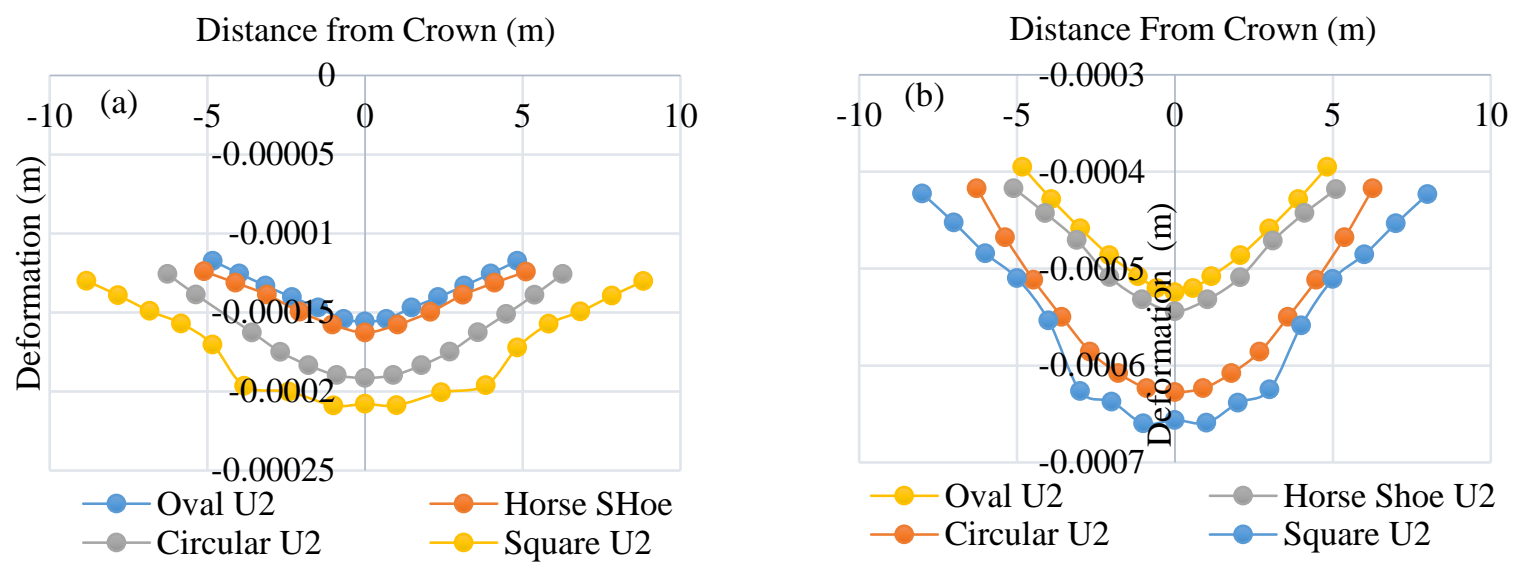

Fig. 11. Deformation across the crown of opening in (a) Granite rock (b) Sandstone rock

\section{CONCLUSION}

In ABAQUS, a three-dimensional finite element study of the tunnel was done. In a current tunneling project, the corresponding tunnel opening size and overhead pressure have been examined. Four potential opening shapes were considered, with a comparison result shown. The results have been discussed in relative parameters to focus the investigation on the effect of opening form exclusively. It has been discovered that the square opening deforms the most at the crown when subjected to the same overburden pressure and opening size. The crown of a horseshoe opening in underground tunnels could be quite near to the oval shape of the opening. However, the most stable invert can be observed in the case of rectangular opening only.

\section{ACKNOWLEDGMENTS}

The authors would like to extend their sincere appreciation to the Research Center, College of Engineering, King Saud University for its support to this Research work.

\section{REFERENCES}

[1] Walhlstrom E.E., Tunneling in Rock. Elsevier (1973); 250

[2] Mahtab M.A., Grasso P. Geomechanics Principles in the Design of Tunnels and Caverns in Rocks. Elsevier Press (1992).

[3] Chaipanna P., Jongpradist P., 3D-fem analysis of shield tunnel construction with groundspring model, International Journal of GEOMATE, March, 2017, Vol 12, Issue 31, pp. 58-62
[4] Khan M.A., Sadique M.R. and Zaid M., Effect of Stratification on Underground Opening: A Numerical Approach, Advances in Transportation Engineering. (2019); 133-142

[5] Naqvi, M. W., Akhtar, M. F., Zaid, M. and Sadique, M. R. (2021). Effect of superstructure on the stability of underground tunnels. Transportation Infrastructure Geotechnology, 8(1), 142-161.

[6] Dang V.K., Dias D., Do N.A., Vo T.H., Impact of blasting at tunnel face on an existing adjacent tunnel, International Journal of GEOMATE, July, 2018 Vol.15, Issue 47, pp.22-31

[7] Khan M.A., Sadique M.R., Harahap I.H., Zaid M., Alam M. M., Static and Dynamic Analysis of the Shielded Tunnel in Alluvium Soil with 2D FEM Model Transportation Infrastructure Geotechnology, $2021 \quad 1-28$ doi.org/10.1007/s40515-021-00160-z.

[8] Das D., Malik J., Deb T., and Das D., Quantification of principal horizontal stresses inside a tunnel: An application of Fracture induced Electromagnetic Radiation (FEMR) technique in the Darjeeling-Sikkim Himalayas Engineering Geology, Vol. 279, 20, 2020, 105882.

[9] Han H., Fukuda D., Liu H., Salmi E.F., Sellers E., Liu T., and Chan A., Combined finitediscrete element modellings of rockbursts in tunnelling under high in-situ stresses. Computers and Geotechnics Vol. 137, 2021, 104261.

[10] Jha, P.C. and Chouhan R.K.S., Long Range Rockburst Prediction: A Seismological Approach. International Journal of Rock Mechanics, Mineral Science, and 
Geomechanical Abstracts 1994; vol. 31, No. 1, pp. 71-77.

[11] ABAQUS User's Manual Version 6.12, MIMULIA, Dassault Systemes Simulia Coro., 2015

[12] Tejal P., Udit J. and Payal Z., Rail link project A case study on Jammu-Udhampur-SrinagarBaramulla, Int. J. Curr. Res. Aca. Rev. 2(2), 2014; 167-172.

[13] Bathe K.J., On some current procedures and difficulties in finite element analysis of elastic plastic response, Computer Structures 1980; 12:607-24.

[14] Ramamurthy T. Engineering in rocks for slope foundations and tunnels. Printice-Hall of India 2007; pp 406.

[15] Abu-Farsakh M.Y. and Tumay M.T., Finite element analysis of ground response due to tunnel excavation in soils. In: Proceeding of the international journal for numerical and analytical methods in geomechanics engineering, AinShams University, Egypt, vol. 23; 1999 p. 524-5.

[16] Chehade F.H. and Shahrour I., Numerical analysis of the interaction between twintunnels: influence of the relative position and construction procedure. J Tunnel Underground Space Technology, 2008; 23:210-4.

[17] Mazek S.A., Law K.T. and Lau D.T., 3-D. Analysis on the performance of a grouted tunnel, Canadian geotechnical conference, Calgary, Canada, vol. 1. p. 111-9.

[18] Mazek S.A., Impact of grouting on an existing tunnel performance under passed by another tunnel. In: Proceeding of the 11th, ICSGE, 1719 May, Cairo, Egypt 2005.

[19] Vermeer P.A. and Moller S.C., Numerical simulation of tunnel installation. J Tunnel Underground Space Technology, 2008; 23:461-75.

[20] Mazek S.A. and Almannaei H.A, Finite element model of Cairo metro Tunnel-Line 3 performance. Ain Shams Engineering Journal 2013; 4, 709-716

[21] Elsayed A., Study of rock-lining interaction for circular tunnels using finite element analysis. Proc Jordan J Civ Eng; 2011; 5(1):50-64.

[22] Cavalaro S.H.P., Blom C.B.M., Walraven J.C. and Aguado A., 14-Structure analysis of control deficiencies in segmented lining. Tunnel Underground Space Technology 2011;26, 651-127.

[23] Valizadeh K.A., Sadaghiani M.H. and Ahmadi M.M., Numerical modelling of ground settlement control large span underground metro station in Tehran metro using central beam column (CBC). Tunnel Underground Space Technology 2012; 28:218-28.

[24] Feng L.J., Taiyue Q. and Zhanrui W., Analysis of ground movement due to metro tunnel station driven with enlarging shield tunnels under building and its parameter sensitivity analysis. Tunnel Underground Space Technology 2012; 28:287-96.

[25] Zhechao W., Wong Ron C.K., Li S. and Liping Q., Analysis of ground movement due to metro tunnel station driven with enlarging shield tunnels under building and its parameter sensitivity analysis. Tunnel Underground Space Technology 2012; 30:85-92.

[26] Yu W., Jaingwei S. and Charles N., Numerical modeling of tunneling effect on buried pipelines. Can Geotech J 2011; 48:1125-37.

[27] Hoek E, Grabinsky M.W. and Diederichs M.S., Numerical modelling for underground excavation design. Trans Inst Min Metall Sect A V 1991;100: A22-30.

[28] Sadique, M.R. and Nawab M.S., Understanding Post-Failure Response of Squeezing Tunnels and Mitigation. Int. J of Global Techno. Initiatives. (2012); 1(1): A31A40.

[29] Zhao Z., Thermal Influence on Mechanical Properties of Granite: A Microcracking Perspective, Rock Mech Rock Eng (2016) 49:747-762 DOI 10.1007/s00603-015-0767-1

[30] Zhang Y., Sun Q., He H., Cao L., Zhang W. and Wang B., Pore characteristics and mechanical properties of sandstone under the influence of temperature, Applied Thermal Engineering 113 (2017) 537-543.

[31] Xiang Y., Zeng Z., Xiang Y., Abi E., Zheng Y. \& Yuan H., Tunnel failure mechanism during loading and unloading processes through physical model testing and DEM simulation, Scientific Reports | (2021) 11:16753 https://doi.org/10.1038/s41598-021-96206-w.

Copyright (C) Int. J. of GEOMATE All rights reserved, including making copies unless permission is obtained from the copyright proprietors. 